\title{
G-BANDING ANALYSIS OF RADIATION-INDUCED CHROMOSOME DAMAGE IN LYMPHOCYTES OF HIROSHIMA A-BOMB SURVIVORS
}

\author{
Kazuo OHTAKI \\ Department of Genetics, Radiation Effects Research Foundation, \\ Minami-ku, Hiroshima 732, Japan
}

\begin{abstract}
Summary The present report describes the G-band analysis of somatic chromosomes in lymphocytes from $63 \mathrm{~A}$-bomb survivors in Hiroshima to determine the type and frequency of radiation-induced chromosome aberrations. (1) The cells with stable-type chromosome aberrations (Cs cells) predominated among the aberrant cells, and showed a dose-dependent increase. All stable chromosome aberrations were classified into nine categories: reciprocal translocations, translocations of complex type, insertions, complex exchanges, peri- and paracentric inversions, terminal and interstitial deletions, and unidentified rearrangements. The frequencies of aberrations were found to increase with increasing dose for all aberration categories. Reciprocal translocations predominate in all dose ranges and among the chromosome aberrations classified. (2) The linear model was fitted to test the dose-response relationship for Cs cell frequencies. Employing a constant neutron RBEs of 10, an estimated linear slope of $15.2 \% / \mathrm{Sv}$ was obtained for DS86 bone marrow dose with an intercept of $2.9 \%$ at dose 0 . (3) Statistical analysis of data on 3,370 break sites showed good correlations between relative DNA content and the distribution of chromosome breaks involved in translocations, although the involvement of chromosome 1 is significantly higher.
\end{abstract}

Key Words chromosome aberrations, G-band, A-bomb survivors, dose-response

\section{INTRODUCTION}

Dicentric and ring chromosomes, termed unstable chromosome aberrations, have long been considered as a sensitive biological indicator of the absorbed radiation dose, because they can be identified efficiently and accurately. However, the use of dicentric chromosome frequencies for biological dosimetry is complicated

Received August 7, 1992; Accepted September 1, 1992 
because the frequency of cells carrying such chromosomes decreases with time after exposure. Furthermore, there are some technical difficulties in scoring stable chromosome aberrations, such as reciprocal translocations and inversions.

In our previous studies using a conventional cytogenetic technique, it had been found (1) that chromosome aberrations persist for decades after exposure to Abomb radiation in circulating lymphocytes of the A-bomb survivors and (2) that the frequency of cells with chromosome aberrations are proportional to the estimated radiation dose assigned to each survivor. Among the chromosome aberrations detected, reciprocal translocations and inversions, customarily referred to as "stable chromosome aberrations," predominate over unstable ones, and thus they are the principal contributor to the dose-response relationship in A-bomb survivors (Awa et al., 1971, 1978; Awa, 1983; Awa et al., 1984; Awa, 1991). Repeat cytogenetic examinations of the survivors have provided evidence that the frequencies of cells with stable aberrations have remained unchanged with time in persons irradiated in viva (Buckton et al., 1978; Buckton, 1983).

Banding methods for identifying individual chromosomes have enabled us to detect more accurately various radiation-induced structural rearrangements, especially those stable chromosome aberrations hitherto undetectable by the conventional staining method; these include paracentric inversions and intra- and inter-chromosomal exchanges with chromosomal segments of equal length.

In our previous study, the type and frequency of chromosome aberrations were determined in 23 Hiroshima A-bomb survivors, first using conventional staining and then G-banding technique for the same metaphases. According to this anal$y$ sis, the scoring efficiency of cells with chromosomal aberrations by conventional staining, relative to that of G-banding, was 0.7-0.8 (Sofuni et al., 1978; Ohtaki et al., 1982), though it varied from case to case. However, no attempt was made in the previous study to analyze the chromosome aberration frequency by estimated radiation dose for individual survivors because of the paucity of cases and of cells per case.

The main purposes of this study are (1) to clarify the types and frequencies of radiation-induced chromosome aberrations as determined by G-banding in $63 \mathrm{~A}$ bomb survivors in Hiroshima, (2) to determine the relationship between chromosome aberration frequencies and DS86 bone marrow doses assigned to each survivor, (3) to analyze the distribution of chromosome breaks involved in the formation of translocations, and (4) to compare the frequencies of the Cs cells between conventional and G-banding analyses for the same A-bomb survivors.

\section{MATERIALS AND METHODS}

Sample Selection. The data consist of the blood samples collected from 1977 to 1987 from A-bomb survivors in the RERF Adult Health Study (AHS) Cohort (Hollingsworth and Beebe, 1960) in Hiroshima. Initially, the study subjects 
were selected randomly for repeat cytogenetic examinations using their estimated radiation dose based on the T65D dosimetry (Milton and Shohoji, 1968). The sample cases in the present analysis were selected as the 2nd program of the cytogenetic study, the detail of which has been described in the report of Preston et al., (1988). Of the 94 survivors selected for the G-banding analysis, excluded were those (1) who were not in the city at the time of bombing (5 cases), (2) who had an estimated DS86 kerma of 4 Gy or more (10 cases), based on the criteria for selection of cases for cytogenetic analyses (Preston et al., 1988), (3) whose dose estimates were not available ( 8 cases) (Roesch, 1987), and (4) who were diagnosed as having cancer ( 8 cases), including those having received radiotherapy. Thus remaining 63 survivors, 11 distally exposed ( $0-G y)$ and 52 proximally exposed $(0.01-$ 3.99 Gy), were eligible for the present analysis, as shown in Table 1.

Among the proximally exposed survivors, 9 were subjected to repeat examination to test whether there were any differences in the types and frequencies of chromosome aberrations. The difference in the mean frequencies of cells with stable-type chromosome aberrations (Cs cells) was not statistically significant ( $\mathrm{p}=$ 0.98 ) between samples obtained from the same individuals. Therefore, combined data on the aberration frequencies from the same survivors were used in this study. Organ dose to the bone marrow was considered appropriate for estimating the dose relationship for chromosome aberrations, using the neutron RBE of 10 (Sposto et al., 1990).

Control consisted of 11 subjects exposed distally, more than 2,500 meters from the hypocenter. The remaining 52 subjects were the survivors exposed proximally with DS86 doses of $0.01 \mathrm{~Sv}$ or more. These survivors were divided into the following 4 dose categories: 0.01-0.99 Sv, 1.00-1.99 Sv, 2.00-2.99 Sv, and 3.00-3.99 Sv.

Table 1. Number of Hiroshima A-bomb survivors selected for G-banding analysis.

\begin{tabular}{l|ccc}
\hline $\begin{array}{c}\text { Exposure } \\
\text { status }\end{array}$ & $\begin{array}{c}\text { DS86 } \\
\text { kerma dose } \\
\text { (Gy) }\end{array}$ & $\begin{array}{c}\text { No. of } \\
\text { cases } \\
\text { sampled }\end{array}$ & $\begin{array}{c}\text { No. of } \\
\text { cases } \\
\text { analyzed }\end{array}$ \\
\hline \multirow{2}{*}{ Distally exposed } & $0-0.004$ & 11 & 11 \\
& $\begin{array}{l}\text { NICa } \\
\text { Subtotal }\end{array}$ & 5 & - \\
\hline \multirow{3}{*}{ Proximally exposed } & $0.01-0.99$ & 16 & 11 \\
& $1.00-1.99$ & 17 & 16 \\
& $2.00-2.99$ & 17 & 16 \\
& $3.00-3.99$ & 9 & 6 \\
& $4.00-$ & 10 & - \\
& unknown & 8 & - \\
\hline
\end{tabular}

a Not-in-city group (see text). 
Further breakdown was made in terms of the number of subjects and of cells examined (Table 2).

Culture methods. Peripheral lymphocytes were cultured using the whole-blood culture method of Hungerford (1965), with an incubation of $52 \mathrm{hr}$ during the period 1977 to 1982, and of $48 \mathrm{hr}$ from 1983 to date. Colchicine was added to the cultures during the last $2 \mathrm{hr}$ of incubation. The culture medium used in this study was Eagle's MEM (GIBCO, Grand Island) until 1982 and RPMI 1640 (GIBCO) since 1983. Preliminary tests showed no differences in chromosome aberration frequencies between 48 and $52 \mathrm{hr}$ of culture or between the two culture media.

Slides were prepared by hypotonic pretreatment with a solution of $0.075 \mathrm{M}$ $\mathrm{KCl}$ and $1 \%$ sodium citrate, followed by treatment with a $3: 1$ methanol/acetic acid solution and air-drying. Ten of the 25 slides per sample were stained for $20 \mathrm{~min}$ with $2 \%$ Giemsa solution for conventional staining analysis. The remaining 15 slides were used for G-banding analysis. The G-banded preparations were a minor modification of the trypsin technique of Seabright (1971); metaphases were treated in a $0.2 \%$ trypsin solution $(1: 250, \mathrm{GIBCO})$ for 10 to $20 \mathrm{sec}$ at room temperature, washed with water to prevent trypsin digestion, and finally stained with a $2 \%$ Giemsa solution for 10 to $15 \mathrm{~min}$.

All slides were coded, and microscopic analyses were carried out without knowledge of individual exposure status. In each case, an attempt was made to analyze 200 metaphases. However, there were a few instances with poor mitoses, in which less than 50 metaphases were analyzable; these were excluded from this study.

All G-banded well-spread metaphases were photographed for karyotype analysis. All of the cells with definite or suspected aberrations in G-banding patterns were karyotyped using the printed photographs to determine the type of radiationinduced chromosome aberrations.

Following the ISCN (1985), stable chromosome aberrations were classified into nine types for aberrations: (1) reciprocal translocations [t], inter-chromosomal interchanges; (2) pericentric inversions [inv-peri], intra-chromosomal interchanges; (3) paracentric inversions [inv-para], intra-arm interchanges; (4) terminal deletions [del-ter], loss of an acentric segment produced from the broken chromosome in the complement; and (5) interstitial deletions [del-int], loss of acentric material in a mid-portion of the broken chromosome arm. Complex aberrations are classified into three groups (Ohtaki et al., 1982): (6) either direct or inverted "insertion [ins]" as a result of three-break rearrangements, (7) translocations of complex type [t-cx] produced from sequential exchanges between broken segments due at least to three breaks, and (8) "complex exchanges [e-cx]" three- or more-break rearrangements by a combination of a reciprocal translocation(s) co-existing with other aberrations such as insertions and inversions that involve more than three breaks. Certain aberrations were so complicated that banding analyses could not specify the types and origins of aberrations, thus they were termed "unidentified" and categorized as 
the 9 th type of aberrations.

\section{RESULTS}

Frequency of cells with chromosome aberrations

Table 2 shows the G-banding data on the frequency of cells with chromosome aberrations. The mean frequencies of $\mathrm{Cs}$ and $\mathrm{Cu}$ cells derived from 1,487 cells in 11 of the distally exposed group, referred to as the control group, were $2.90 \%$ and $1.01 \%$, respectively, whereas those from the 8,103 metaphases in 52 of the proximally exposed group were $25.87 \%$ and $1.00 \%$, respectively. In the exposed group, more than $95 \%$ of the total aberrant cells were occupied by Cs cells. In contrast, there was no difference in frequencies of $\mathrm{Cu}$ cells between control and exposed groups; i.e., $1.01 \%$ versus $1.00 \%$. The aberrant cell frequencies in the exposed group were further classified into 4 dose categories; 0.01-0.99 Sv, 1.00-1.99 Sv, 2.00-2.99 Sv, and 3.00-3.99 Sv. There was a dose-dependent increase in Cs cell frequencies as shown in Table 2: $10.61 \%, 26.11 \%, 38.74 \%$, and $46.61 \%$ for $0.01-$ $0.99 \mathrm{~Sv}, 1.00-1.99 \mathrm{~Sv}, 2.00-2.99 \mathrm{~Sv}$, and 3.00-3.99 Sv, respectively. Here again, no consistent increase in $\mathrm{Cu}$ cell frequencies was observed.

Types and frequencies of chromosome aberrations

Stable aberrations. Table 3 shows the frequencies in percentage for each of the nine stable chromosome aberration types described above, with further breakdown by 4 dose groups for the proximally exposed. In the control group, all types of aberrations were observed. In particular, both translocations and terminal

Table 2. Mean frequencies (\%) of aberrant cells by G-band.

\begin{tabular}{|c|c|c|c|c|c|c|c|}
\hline \multirow{2}{*}{ Group } & \multirow{2}{*}{$\begin{array}{l}\text { Dose } \\
(\mathrm{Sv})^{\mathrm{a}}\end{array}$} & \multirow{2}{*}{$\begin{array}{l}\text { Mean } \\
\text { dose } \\
(\mathrm{Sv})\end{array}$} & \multirow{2}{*}{$\begin{array}{c}\text { No. of } \\
\text { subjects }\end{array}$} & \multirow{2}{*}{$\begin{array}{l}\text { Total } \\
\text { cells } \\
\text { examined }\end{array}$} & \multicolumn{3}{|c|}{$\%$ of aberrant cells } \\
\hline & & & & & Cs cells & $\mathrm{Cu}$ cells b & Total \\
\hline Dist. & $0-0.004$ & 0 & 11 & 1,487 & $\begin{array}{r}2.90 \\
( \pm 1.66)\end{array}$ & $\begin{array}{c}1.01 \\
( \pm 0.59)\end{array}$ & $\begin{array}{r}3.91 \\
( \pm 2.03)\end{array}$ \\
\hline \multirow[t]{5}{*}{ Prox. } & $0.01-0.99$ & $\begin{array}{c}0.536 \\
( \pm 0.291)\end{array}$ & 19 & 1,783 & $\begin{array}{c}10.61 \\
( \pm 7.62)\end{array}$ & $\begin{array}{c}0.78 \\
( \pm 0.87)\end{array}$ & $\begin{array}{r}11.39 \\
( \pm 7.87)\end{array}$ \\
\hline & $1.00-1.99$ & $\begin{array}{c}1.555 \\
( \pm 0.326\rangle\end{array}$ & 18 & 3,381 & $\begin{array}{c}26.11 \\
( \pm 9.96)\end{array}$ & $\begin{array}{c}1.05 \\
( \pm 0.99)\end{array}$ & $\begin{array}{r}27.17 \\
( \pm 10.24)\end{array}$ \\
\hline & $2.00-2.99$ & $\begin{array}{r}2.354 \\
( \pm 0.256)\end{array}$ & 12 & 2,199 & $\begin{array}{r}38.74 \\
( \pm 11.31)\end{array}$ & $\begin{array}{c}0.99 \\
( \pm 1.03)\end{array}$ & $\begin{array}{r}39.73 \\
( \pm 11.18)\end{array}$ \\
\hline & $3.00-3.99$ & $\begin{array}{c}3.371 \\
( \pm 0.129)\end{array}$ & 3 & 740 & $\begin{array}{c}46.61 \\
( \pm 7.57)\end{array}$ & $\begin{array}{r}1.61 \\
( \pm 1.15)\end{array}$ & $\begin{array}{c}51.22 \\
( \pm 6.88)\end{array}$ \\
\hline & Subtotal & & 52 & 8,103 & $\begin{array}{r}25.87 \\
( \pm 15.52)\end{array}$ & $\begin{array}{c}1.00 \\
( \pm 0.98)\end{array}$ & $\begin{array}{r}26.86 \\
( \pm 15.73)\end{array}$ \\
\hline
\end{tabular}

a DS86 Bone Marrow dose (neutron RBE of 10). b No dose dependent increase in Cu cells frequencies was observed $(\mathrm{p}=0.36)$. Dist., distally exposed group; Prox., promixally exposed group. 
Table 3. Mean frequencies (\%) of chromosome aberrations by G-band in $63 \mathrm{~A}$-bomb survivors.

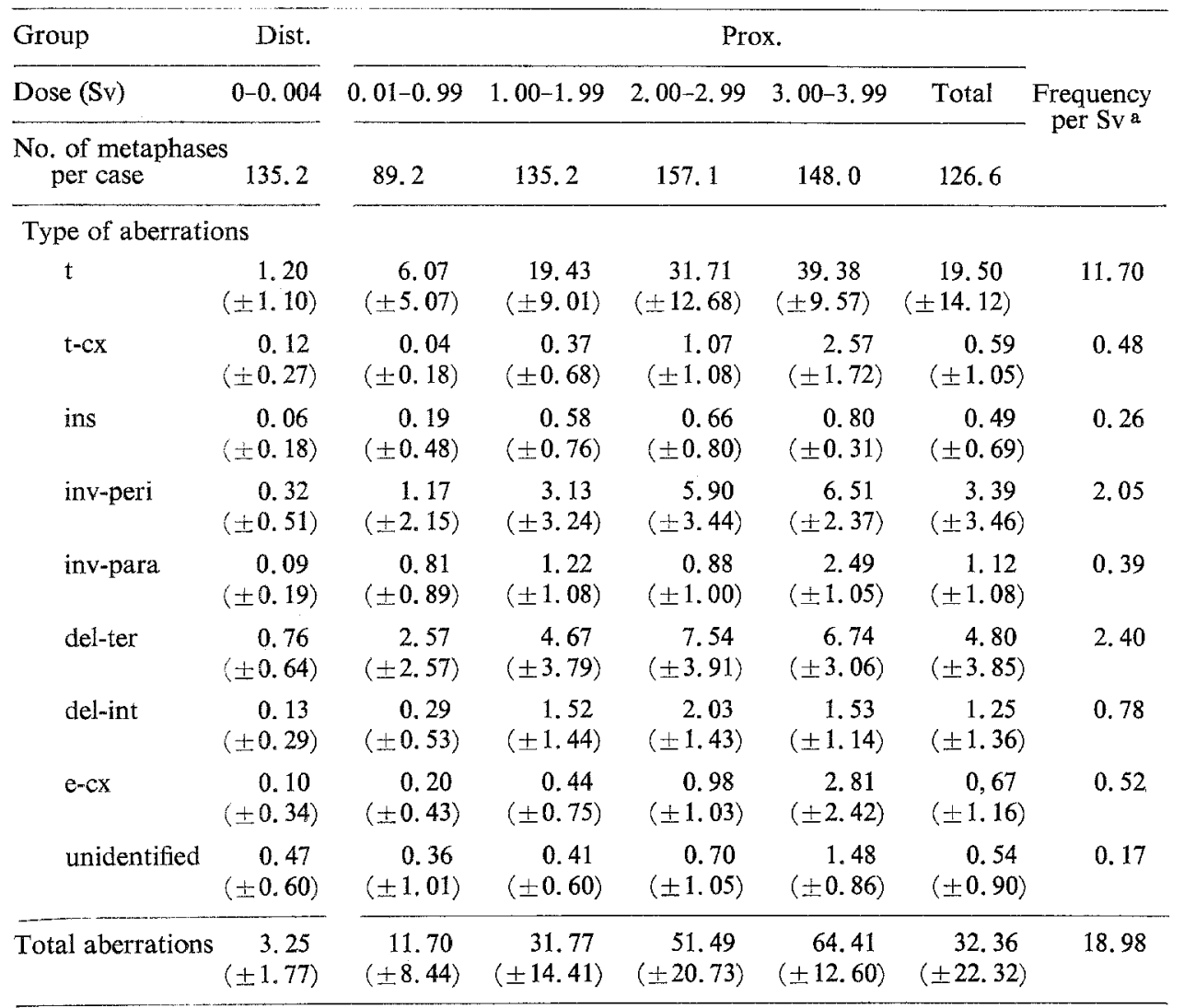

a Computed using linear regression models. The rate indicates the change in the percentage of aberrations per Sievert. $t$, reciprocal translocations; $t-c x$, translocations of complex type; ins, insertions; inv-peri, pericentric inversions; inv-para, paracentric inversions; del-ter, terminal deletions; del-int, interstitial deletions; e-cx, complex exchanges; Dist., distally exposed group; Prox., proximally exposed group.

deletions were found to be predominant, being $43 \%$ and $22 \%$ of the total aberrations, respectively, i.e., translocation frequency in the control was $1.2 \%$ of the total cells observed.

General features for the presence of chromosome aberrations in the exposed group were as follows: all nine types of aberrations increased almost linearly with increasing bone-marrow dose. As anticipated, frequencies of complex exchanges such as $\mathrm{t}-\mathrm{cx}$ and $\mathrm{e}-\mathrm{cx}$, as well as the unidentifiable type, increased sharply with increasing doses. The predominance of reciprocal translocations was demonstrated in all dose categories, ranging from $53 \%$ in the $0.01-0.99 \mathrm{~Sv}$ dose category to $67 \%$ in the 3.00-3.99 Sv category. The translocation frequency per Sv was $11.70 \%$, being the highest among all types of stable aberrations. The present results con- 
firmed earlier observations that translocations are primary contributors to the doseresponse relationship in A-bomb survivors. This finding seems relevant to the use of the fluorescence in situ hybridization (FISH, or "chromosome painting") technique to measure translocation frequency as a biological indicator for persons exposed to irradiation in vivo.

There was also a dose-dependent increase in the frequency of inversions, both inv-peri and inv-para types. It is noteworthy that inversions of paracentric type can be identified only using G-banding analysis. The absolute values of interstitial deletions, del-int, were low in frequency, but their increase with radiation dose was also noted.

For the remaining types of chromosome aberrations, mean frequencies per $\mathrm{Sv}$ increase with increasing bone-marrow doses, as shown in the right column of Table 3.

Some of the aberration types were known to be undetectable by the conventoinal staining analysis. For example, insertions [ins] cannot be discriminated from usual reciprocal translocations. The same was true for deletions between terminal [del-ter] and interstitial [del-int] types.

The stable aberration frequency per aberrant cell showed a tendency to generally increase with increasing doses (data not shown here).

Unstable aberrations. As for unstable chromosome aberrations, there were 3 dicentrics and 9 acentrics that were associated with neither dicentrics nor rings, in the controls, whereas there were 39 dicentrics, 12 rings, and 29 acentrics in the exposed group. As mentioned above, there was no substantial difference in unstable aberration frequencies between control and exposed groups.

Cells having more than 5 unstable exchange aberrations of unidentifiable nature were observed both in control and exposed groups ( 2 cells in the control, and 4 cells in the exposed). They were termed "cells with multiple chromosome aberrations," some of which resembled "rogue" cells as reported by Awa and Neel (1986) and were excluded from the analysis.

\section{Relationship between radiation dose and aberration frequency}

The number of Cs cells are revealed by G-banding analysis and the total number of cells examined for each sample were used in describing the relationship between the proportion of aberrant cells and dose. For this purpose, binomial regression models of the form

$$
\mathrm{E}(\mathrm{a} ; \mathrm{n})=\mathrm{np}=\mathrm{n} \beta \mathrm{x}
$$

have been used, where for each sample a is the observed number of cells with aberrations, $\mathrm{n}$ is the total number of cells scored, $\mathrm{p}$ is the estimated proportion of cells with aberrations, $x$ is a vector of covariates including functions of dose in Sv, and $\beta$ is a vector of parameters (see Preston et al., 1988). In the standard binomial regression model, the variance of an observation depends on the true value of $p$, in particular 


$$
\mathrm{V}(\mathrm{a} ; \mathrm{n})=\mathrm{np}(\mathrm{l}-\mathrm{p})
$$

In the previous cytogenetic studies using conventional method, it was found that the variability of the observed number of Cs cells among persons within a dose category appeared to be much greater than one would expect with a binomial model in which the aberration rate was a linear or quadratic function of dose. A recent study by Pierce et al. (1989) indicated that random errors in radiation exposure estimates would cause part of the overdispersion of Cs cell frequencies. To adjust for this overdispersion, it is assumed that, given $p$, the variance of the number of Cs cells is given by

$$
\mathrm{V}(\mathrm{a} ; \mathrm{n})=\mathrm{np}(1-\mathrm{p})+\rho(\mathrm{np})^{2},
$$

where $\rho$ is a parameter to be estimated. This model does not differ appreciably from the beta-binomial model (Preston et al., 1988). In the present study, the estimation of the parameter vector $\beta$ and $\rho$ was made using iteratively reweighted least squares with the weights at each iteration determined by the variance function. This corresponds to the iterative use of the method of quasi-likelihood.

Figure 1 shows the frequencies of Cs cells for individual survivors plotted against DS86 bone-marrow dose employing a constant neutron RBE of 10. Coefficients for both linear and linear-quadratic models derived from Eqs. (1) to (3)

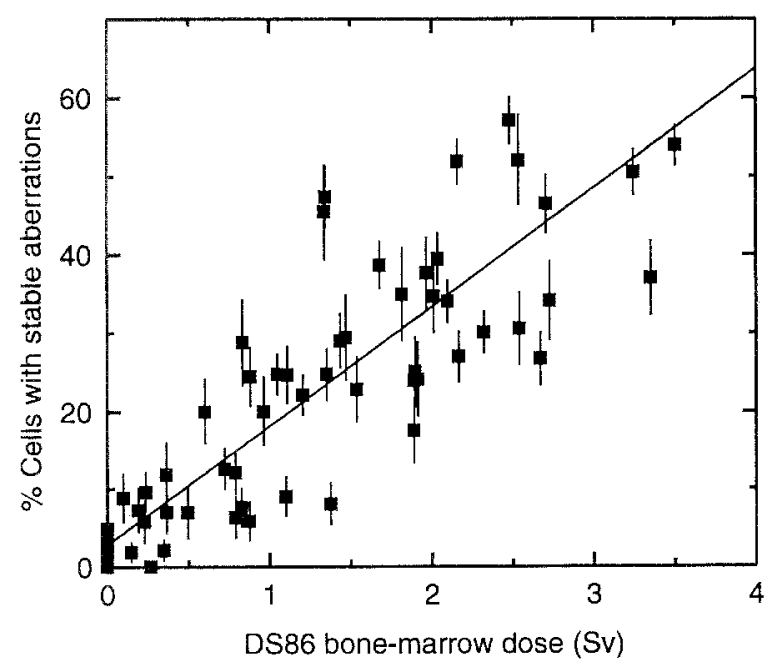

Fig. 1. The frequencies of Cs cells are plotted against the DS86 dose to the bone marrow, assuming a neutron RBE of 10 . The solid line shows a regression line through data on 52 proximally exposed and 11 distally exposed survivors. Parameter estimates in the linear model were computed by quasi-likelihood models allowing for overdispersion (Preston et al., 1988). Cs cell data were obtained from the G-banding analysis. Error bars show the uncertainty for the individuals (one standard deviation). 
Table 4. Regression coefficients and significance tests in linear and linear-quadratic models of the percentage of cells with stable aberrations.

\begin{tabular}{lllc}
\hline Dosimetry & Model & \multicolumn{2}{c}{ Regression coefficients } \\
\hline DS86 bone marrow dose (Sv) & Linear model & Intercept & $2.9 \pm 0.50$ \\
& & Slope & $15.2 \pm 1.08$ \\
& Linear-quadratic model & $\rho$ & 0.13 \\
& & Intercept & $2.8 \pm 0.51$ \\
& & Linear & $16.7 \pm 2.65$ \\
& & Quadratic & $-0.8 \pm 1.25$ \\
& & $\rho$ & 0.13
\end{tabular}

Parameter estimates were computed using quasi-likelihood models that allow for overdispersion. The intercept is an estimate of the percentage of cells with aberrations among persons whose estimated dose is $0 \mathrm{~Sv}$. The slope indicates the change in the percentage of cells with aberrations per $\mathrm{Sv} ; \rho$ is the overdispersion parameter (Preston et al., 1988).

for the present G-banding data are shown in Table 4 , in terms of the values for the intercept (at the $0-\mathrm{Sv}$ level), the slope (aberration frequency per Sv), and $\rho$ (overdispersion parameter).

The data on the present statistical analysis indicated that, for the linear regression model, the slope of $15.2 \pm 1.1 \%$ and the intercept of $2.9 \pm 0.5 \%$, with an overdispersion parameter $\rho$ of 0.13 , were obtained. The values for the first term of $16.7 \pm 2.7 \%$, second term of $-0.8 \pm 1.25 \%$, and the intercept of $2.8 \pm 0.5 \%$ with a $\rho$ of 0.13 gave the best fit to the linear-quadratic model. The present results indicated that the dose-response for stable aberration frequencies in Hiroshima survivors can be best fitted to the linear model. For the linear-quadratic model, the quadratic term was negative, though it was not statistically significant.

The variability in Cs cell frequencies in a given dose range was still observable. This means that there is a small fraction of survivors whose aberration frequencies were grossly discrepant with regard to the estimated dose assigned to the survivors. Although the data are not shown here, the degree of overdispersion in aberration frequencies did not seem to differ significantly between the survivors with severe epilation and those with mild or no epilation immediately after exposure. Further analyses in stable aberration frequencies are under way in terms of breakdown by various shielding categories.

\section{Comparison of Cs cell frequencies between conventional and $G$-banding methods}

As mentioned earlier, certain types of chromosome aberrations are undetectable by the use of the conventional staining method (Ohtaki et al., 1982), such as reciprocal translocations of chromosome segments with equal length, paracentric inversions, etc. This has caused substantial reduction in scoring efficiency for radiation-induced chromosome damage for biological dosimetry using the current 
standard procedure.

To evaluate the power of scoring efficiency on the detection of stable chromosoem aberrations measured using conventional cytogenetic methods, a comparison was made of the frequencies of Cs cells between G-banding and conventional staining data for the same survivors, with the assumptions that G-banding analysis can detect all induced chromosome aberrations with a full efficiency and that the frequency of $\mathrm{Cs}$ cells induced in vivo in the somatic cells does not change with time. The results, shown in Fig. 2 are based on the data available from both methods from 62 survivors in Hiroshima. The ratio of conventional frequencies to the corresponding G-banding values was 0.70 , with the regression coefficient $r=0.94$ $(\mathrm{p}<0.001)$. The present data indicated that, although the scoring efficiency by the conventional method was reduced by about $30 \%$, the correlation between the two methods was good. This result confirmed our previous finding that the detection rate of conventional to G-banding was 0.75 (Ohtaki et al., 1982). The same tendency has also been observed in translocation frequencies measured with FISH and G-banding analyses (Lucas et al., 1992).

\section{Comparison between in vivo translocation and in vitro dicentric frequencies}

It has been considered that the proportion of peripheral blood lymphocytes with only stable aberrations has remained almost unaltered with time. Unfortunately, it is by no means possible at present to verify the frequencies of translocations produced in survivors immediately after A-bomb exposure. In order to

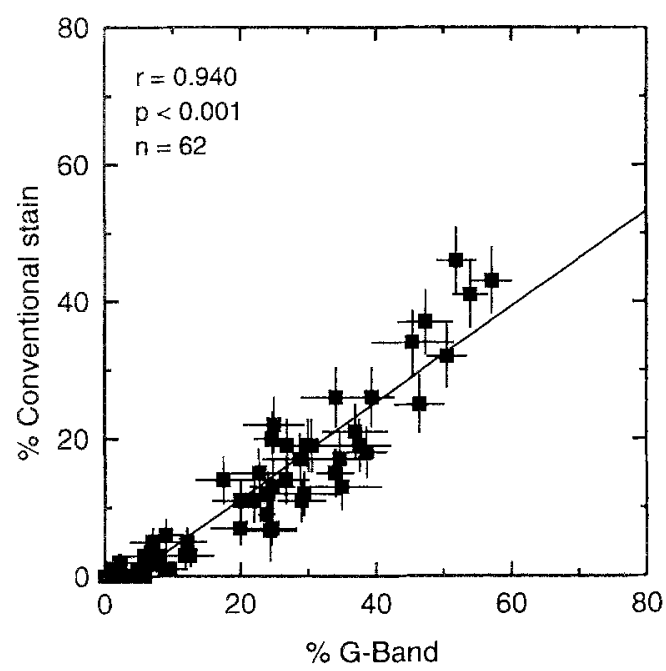

Fig. 2. Comparison of $\mathrm{Cs}$ cell frequencies estimated using conventional and $\mathrm{G}$-banding methods. Conventional vs. G-banding analysis: Cs cell frequencies measured using conventional staining method were plotted against aberrant cell frequencies measured by G-banding for the same individual survivors (solid squares). Error bars show the uncertainty in the counting statistics. 
evaluate the persistence of translocations produced in vivo by exposure to A-bomb radiation, the translocation frequencies in A-bomb survivors were compared with the data from Bender et al. (1988) on the frequencies of dicentrics produced in vitro by exposure to gamma irradiation.

As shown in Fig. 3, each point represents the average number of translocations per cell for the individual survivor, with a computed linear regression as indicated by a solid line. The mean frequency per $\mathrm{Sv}$ is $11.7 \%$ as shown in Table 3 . The dose-response curve for dicentric frequencies yielded by in vitro gamma irradiation is shown by a dotted line fitted to the linear-quadratic model. Figure 3 shows that the level of translocation frequencies in A-bomb survivors generally agreed with the in vitro dicentric frequencies measured with conventional staining method up to $2.5 \mathrm{~Sv}$. However, as the dose increases, the translocation frequencies fall off around $3 \mathrm{~Sv}$. Such a leveling off of the dose-response curve above $2 \mathrm{~Sv}$ may be due to the in vivo elimination of cells having a translocation (or translocations) coexisting with a dicentric(s) that had been produced more preferentially by exposure to high doses of irradiation in survivors. This is one of the reasons why the linear doseresponse relationship for translocation frequencies is applicable to Hiroshima Abomb survivors.

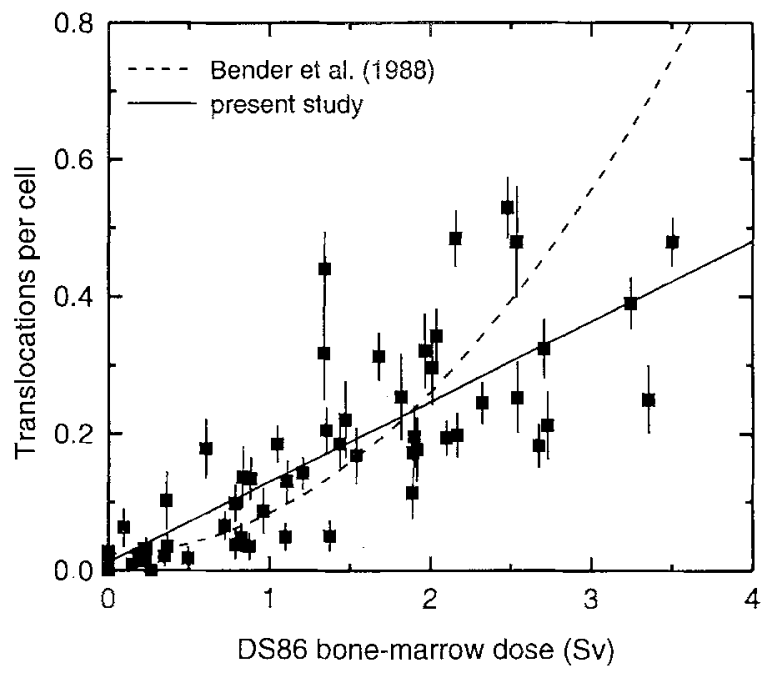

Fig. 3. Comparison of the in vitro dose-response curves dicentric frequency from analysis of ${ }^{\circ 0} \mathrm{Co}$-irradiated lymphocytes (dashed line) with the reciprocal translocation frequencies dose-response data (solid squares) for A-bomb survivors using G-banding. The dashed line shows a dose-response curve for dicentric frequency from the data summarized by Bender et al. (1988). The solid line indicates the linear regression line for frequency of reciprocal translocations in A-bomb survivors against DS86 assigned dose (Sv). Error bars show the uncertainty in the counting statistics. 
Distribution of chromosome breaks involved in translocations

It has been thought that radiation-induced chromosome breaks and subsequent rejoining to form exchange aberrations are produced randomly. It then follows that the frequency of translocations involving each chromosome should be proportional to its relative DNA content. This possibility was investigated by comparing the DNA content of each chromosome with the frequency of chromosome breaks involved in all of the translocations detected. Chromosome break data were derived from 27 males and 25 females in the exposed group, with a total of 3,370 break points involved exclusively in translocations. The relative DNA content data are from Mayall et al. (1984). The results are plotted in Fig. 4. Linear regression analysis of these data showed that the translocation frequency for the $i^{\text {th }}$ chromosome, $F_{i}$ increased with relative DNA content, $d_{i}$, according to the relation: $F_{i}=0.0039+0.91 d_{i}$. The correlation coefficient between translocation frequency and relative DNA content was 0.92 . Only the translocation frequency from chromosome 1 was significantly off the regression line $(p<0.05)$ by the test based on standardized residual (Weisberg, 1980).

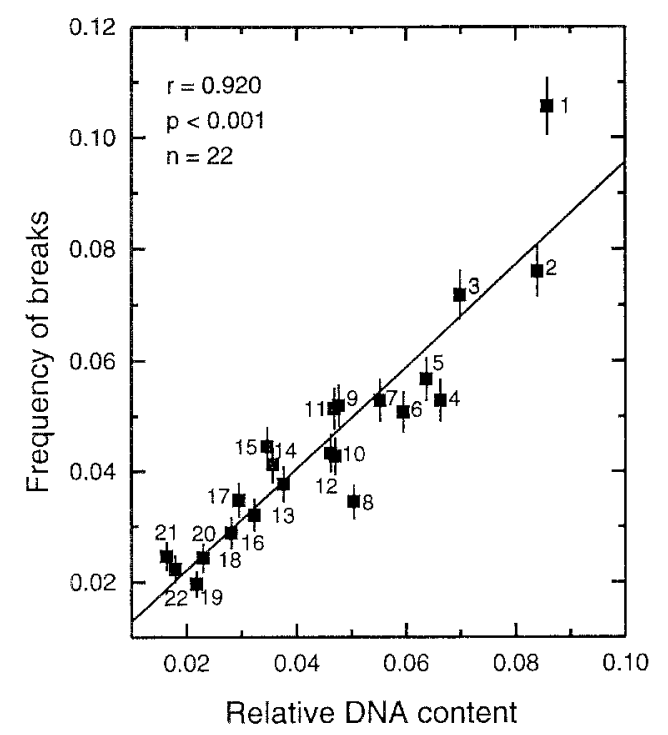

Fig. 4. A plot of the frequency of chromosome breaks involved in reciprocal translocations through chromosome 1 to 22 as a function of chromosomal DNA content. These data were determined from 3,370 breaks involving reciprocal translocations identified by G-banding in Hiroshima A-bomb survivors proximally exposed. 


\section{DISCUSSION}

The dose-response relationship for the frequencies of cells with chromosome aberrations has been demonstrated by Awa et al. $(1971,1978)$ and Preston et al. (1988) in the peripheral blood lymphocytes of A-bomb survivors in Hiroshima and Nagasaki using the conventional cytogenetic method. Furthermore, the linear dose-response model may best be fitted to the aberration data on Hiroshima survivors.

The major objective of this report was to analyze chromosome aberration data, especially with regard to the identification and classification of stable chromosome aberrations using the trypsin-G-banding method of Seabright (1971) to score all kinds of chromosome aberrations detectable by this method, some of which were not identifiable heretofore by the conventional (non-banded) methods. Special emphasis was thus placed on the elucidation to the dose-response relationship for Cs cell frequencies in Hiroshima A-bomb survivors, since there had been no relevant data using G-banding analysis.

As described earlier (Sofuni et al., 1978; Ohtaki et al., 1982), the present study also revealed that not only simple forms of chromosomal interchanges but also multiple exchanges involving more than three breakages of chromosomes (designated as $\mathrm{t}-\mathrm{cx}$ and $\mathrm{e}-\mathrm{cx}$ in this classification) were detectable in the somatic cells of A-bomb survivors. Complex changes were more prevalent in heavily exposed survivors. As indicated in the RESULTS, all the stable chromosome aberrations observed were classified into nine categories. A dose-dependent increase in the frequency was noted for all types of aberrations. Of the nine types of stable aberrations, reciprocal translocations were found to predominate and were the principal contributors to the overall dose-response relationship in the somatic cells of survivors even more than four decades after the exposure to A-bomb radiations.

In any category of stable chromosome aberrations, the majority were of the balanced type; there appeared to be no loss or gain of chromosome materials resulting from the break and rejoining that led to exchanges. Inversions of the paracentric type were known to be undetectable by the non-banded analysis. This type of aberrations was found to contribute only to $3.5 \%$ of the total aberrations (or $25 \%$ of the total inversions).

It is noteworthy that a small fraction of cells that lose a portion of chromosomes, defined as "deletions," has been detected even by the non-banded conventional analysis (Awa et al., 1977). However, the conventional cytogenetic method could not discriminate between two types of deletions, terminal and interstitial. In this study, about $20 \%$ of the total deletions were identified as the "interstitial" type. These observation indicate that the some cells lacking a portion of the chromosomes, as in the monosomic state, could survive in vivo in the circulating lymphocytes.

Vol. 37, No. 4, 1992 
No data aave been avalabie to date on the dose-response relationship for transiocation frequencies in A-bomb survivors with regard to the use of the Gbanding method. Therefore, attempts were made to obtain a dose-response curve for Hiroshima A-bomb survivors using stable aberration frequency data obtained by the present analysis. There was good agreement between aberration frequencies and bone-marrow doses assigned to survivors (in Sv), by applying both linear and linear-quadratic models, as reported by Preston et al. (1988). It is important to note that in this analysis the dose-square term was negative, but not significantly different from zero, indicating a better fit with the linear model in Hiroshima. The increase in the percentage of Cs cells was measured as $15.2 \%$ per Sv, about 1.4 times higher than that derived from the conventional data on 62 Hiroshima survivors. When fitting linear-quadratic values obtained by in vitro gamma irradiation experiments (Bender et al., 1988) to the present data, the regression coefficient was significantly off the level at $2 \mathrm{~Sv}$.

For reciprocal translocations, a tendency was seen that the longer chromosomes were more frequently involved in the exchange formations. Furthermore, as far as the non-banded conventional technique is applied, there is a considerably lower frequency of chromosomes in the C group (or chromosomes 6-12) than the expected theoretically (Awa et al., 1977). However, this kind of disadvantage for the bias of the detection of radiation-induced chromosome rearrangements can be removed by the use of various banding techniques, G-banding in particular.

There have been several reports concerning the frequency of radiation-induced chromosome breaks derived from lymphocytes either irradiated in vitro (Holmberg and Jonasson, 1973; Cooke et al., 1975; Buckton, 1976) or from persons irradiated in vivo (Barrios et al., 1989) to see if there are any preferential occurrence of breaks for particular chromosomes. Recently, Gray et al. (1991) summarized the data from several reports and pointed out that the frequencies of chromosome breaks are more or less proportional to the chromosomal DNA content for each of the chromosomes, with the exception that the frequency of aberrations involving chromosome $I$ is consistently higher than anticipated. Evidence thus presented shows that the distribution in the number of breaks for all chromosomes produced by ionizing radiation is random. A similar pattern to that found by Gray et al. (1991) has also been observed by Lucas et al. (1992) and by the present report using data on Hiroshima survivors.

Tanaka et al. (1983) analyzed the distribution of 1,375 breaks identified in the chromosome aberrations in the lymphocytes of 39 Hiroshima A-bomb survivors and found that the breaks were nonrandomly distributed in certain chromosomes; i.e., chromosomes 15, 18, and 22 are more frequently involved, whereas chromosomes 1,2 , and $X$ were the least involved.

By analyzing chromosome aberrations in patients treated with $\mathrm{X}$ rays for ankylosing spondylitis, Buckton (1983) aimed at establishing whether damage to particular chromosomes is more readily accepted by the cell, with an assumption 
that the number of times that a chromosome will be involved in a rearrangement is proportional to its length. Using the number of chromosome breaks for translocations and dicentrics, she found that among the translocations A-, B-, and Fgroup chromosomes are underrepresented (chromosomes 3 and 19 in particular, but with the exception of chromosome 4), whereas those of chromosomes 9,10 , 14, and 15 are overrepresented.

When the data from Tanaka et al. (1983) and Buckton (1983) are combined with those from the present study, nonrandomness in the distribution of chromosomes participating in the radiation-induced chromosome exchanges becomes less striking as more of the breaks are accumulated. The most discrepant findings among these studies were the involvement of chromosome 1 high frequency in this study but low frequency in others. The reason for this discrepancy remains unknown.

In the routine cytogenetic examinations on Hiroshima A-bomb survivors, a wide variability of aberrant cell frequencies is seen among individual survivors in a given dose range. In particular, aberration frequencies are grossly discrepant in a small fraction of survivors with regard to the dose assigned to each case. They have been termed biological outliers. The same tendency has also been noted for a few exceptional cases, in whom high aberration frequency is seen in the low dose range and low aberration frequency in the high dose range. These outliers are confusing factors that may alter the shape of dose-response curves for the frequencies of aberrant cells. An overdispersion (Preston et al., 1988; Awa, 1989) in aberrant cell frequencies either might be due to random errors in the DS86 estimates for individual survivors or might suggest differential radiation sensitivity among Abomb survivors. Nakamura et al. (1989) studied possible differences in individual radiosensitivities in A-bomb survivors. Using colony formation methods, comparisons of the data from repeated examinations of one person with data from single examinations of different persons showed that variation of the $D_{10}$ value was not significantly greater in the latter group. They have suggested that variation in lymphocyte radiosensitivity among individuals is quite small.

Recently, Sposto et al. (1990) reported the results of a statistical analysis using data on chromosome aberration frequencies correlated with severe epilation. They have shown that the dose-response relationship using the DS86 assigned dose is significantly steeper in the subsample of individuals who reported severe epilation after the bombing than among those who did not. By statistical analyses of these data over a range of dosimetry error models, they concluded that random dosimetry errors in the range $45 \%$ to $50 \%$ of true dose are necessary to explain completely the difference in dose response between the two epilation groups. This level of dosimetry error also accounts for the overdispersion in the proportion of cells with chromosome aberrations. The same tendency has also been observed among the severe epilators for the mortality risk of leukemia in the A-bomb survivors by Neriishi et al. (1989). 
Similarly, Pierce et al. (1989) have investigated the effect of dose errors on inferences based on the cancer mortality data in RERF. In their paper, they suggested that $35 \%$ dosimetry errors may be used in adjusting for dosimetry errors.

Recently, the new FISH technique, described earlier, has allowed rapid, accurate detection of translocations involving painted and non-painted chromosomes. The present G-banding data have provided basic biological information, such as the relationship between the number of breaks involved in the chromosome exchanges and relative DNA content of each chromosome, needed to determine whether the FISH technique is readily applicable to routine cytogenetic screening for biological dosimetry.

The data derived from G-banding analysis are indeed accurate and can provide important information on the dose-response relationship of chromosome aberration frequencies of individual A-bomb survivors. The disadvantages of this technique are that it is laborious and time-consuming and it requires expertise for karyotype analysis for identification of all kinds of induced chromosome aberrations. This technique will be used more efficiently in combination with other methodologies, such as the FISH technique, for biological evaluation of previous exposures to ionizing radiation.

Acknowledgments The author would like to thank very much Dr. Akio A. Awa, Chief of the Department of Genetics, RERF, for many helpful discussions and data analyses during the course of this work, and is much indebted to Dr. Shozo Sawada, Professor of the Department of Radiation Biology, Research Institute for Nuclear Medicine and Biology, Hiroshima University; Mr. Eiji Nakashima, Department of Statistics, RERF, Dr. Toshio Sofuni, Division of Mutagenesis, Biological Safety Research Center, National Institute of Hygienic Sciences and Mr. Hachiro Shimba, Archives, Publication and Documentation Center, RERF, for their encouragement and keen interest in this study. The author is also grateful to all members of the RERF Cytogenetics Laboratory for their continued cooperation and technical assistance.

\section{REFERENCES}

Awa AA (1983): Chromosome damage in atomic bomb survivors and their offspring-Hiroshima and Nagasaki. In: Ishihara $T$ and Sasaki MS (eds). Radiation-induced chromosome damage in man. Alan R Liss Inc, New York, pp 433-453

Awa AA (1989): Chromosome aberrations in A-bomb survivors, Hiroshima and Nagasaki. In: Obe $\mathrm{G}$ and Natarajan AT (eds). Chromosomal aberrations: basic and applied aspects. SpringerVerlag, Berlin, pp 180-190

Awa AA (1991): A Review of forty-five years study of Hiroshima and Nagasaki atomic bomb survivors. II. Biological effects. Persistent chromosome aberrations in the somatic cells of A-bomb survivors, Hiroshima and Nagasaki. J Radiat Res 265-274 (Suppl)

Awa AA, Neel JV(1986): Cytogenetic "rogue" cells:What is their frequency, origin, and evolutionary significance? Proc Natl Acad Sci USA 83: 1021-1025

Awa AA, Neriishi S, Honda T, Yoshida MC, Sofuni T, Matsui T (1971): Chromosome-aberration frequency in cultured blood-cells in relation to radiation dose of A-bomb survivors. Lancet 2: $903-905$

Awa AA, Sofuni T, Honda, T, Itoh M, Neriishi S, Otake M (1977): Relationship between dose 
and chromosome aberrations in atomic bomb survivors, Hiroshima and Nagasaki. RERF TR $12-77$

Awa AA, Sofuni T, Honda T, Itoh M, Neriishi S, Otake M (1978): Relationship between the radiation dose and chromosome aberrations in atomic bomb survivors of Hiroshima and Nagasaki. J Radiat Res 19: 126-140

Awa AA, Sofuni T, Honda T, Hamilton HB, Fujita S (1984): Preliminary reanalysis of radiationinduced chromosome aberrations in relation to past and newly revised dose estimates for Hiroshima and Nagasaki A-bomb survivors. In: Eisert WG and Mendelsohn ML (eds). Biological dosimetry. Springer-Verlag, Berlin, pp 77-82

Barrios L, Miro R, Caballin M, Fuster C, Guedea F, Subias A, Egozcue J (1989): Cytogenetic effects of radiotherapy. Breakpoint distribution in induced chromosome aberrations. Cancer Genet Cytogenet 41: 61-70

Bender MA, Awa AA, Brooks AL, Evans HJ, Groer PG, Littlefield LG, Pereira C, Preston RJ, Wachholz BW (1988): Current status of cytogenetic procedures to detect and quantify previous exposures to radiation. Mutat Res 196: 103-159

Buckton KE (1976): Identification with $G$ and $R$ banding of the position of breakage points induced in human chromosomes by in vitro X-irradiation. Int J Radiat Biol 29: 475-488

Buckton KE (1983): Chromosome aberrations in patients treated with X-irradiation for ankylosing spondylitis. In: Ishihara $\mathrm{T}$ and Sasaki MS (eds). Radiation-induced chromosome damage in man. Alan R Liss Inc, New York, pp 491-511

Buckton KE, Hamilton GE, Paton L, Langlands AO (1978): Chromosome aberrations in irradiated ankylosing spondylitis patients. In: Evans HJ and Lloyd DC (eds). Mutagen-induced chromosome damage in man. Univ Press, Edinburgh, pp 142-150

Cooke P, Seabright M, Wheeler M (1975): The differential distribution of X-ray induced chromosome lesions in trypsin-banded preparations from human subjects. Humangenetik 28: 221-231

Gray JW, Lucas J, Pinkel D, Awa AA (1991): Molecular cytogenetics and biological dosimetry. The proceedings of the US National Council on Radiation Protection.

Hollingsworth JW, Beebe GW (1960): ABCC-JNIH Adult Health Study provisional research plan. ABCC TR 9-60

Holmberg M, Jonasson J (1973): Preferential location of X-ray induced chromosome breakage in the R-bands of human chromosomes. Hereditas 74: 57-68

Hungerford DA (1965): Ieukocytes cultured from small inocula of whole blood and the preparation of metaphase chromosomes by treatment with hypotonic KCl. Stain Technol 40: 333338

ISCN (1985): An International System for Human Cytogenetic Nomenclature. Harnden DG and Klinger HP (eds). Birth defects: Original Article Series, Vol 21, No 1, White Plains, March of Dimes Birth Defects Foundation, New York

Lucas, JN, Awa AA, Straume T, Poggensee M, Kodama Y, Nakano M, Ohtaki K, Weier HU, Pinkel D, Gray J, Littlefield G (1992): Rapid translocation frequency analysis in humans decades after exposure to ionizing radiation. Int $\mathrm{J}$ Radiat Biol 62: 53-63

Mayall BH, Carrano AV, Moore II DH, Ashworth L, Bennett DE, Mendelsohn M (1984): The DNA-based human karyotype. Cytometry $5: 376-385$

Milton RC, Shohoji T (1968): Tentative 1965 radiation dose estimation for atomic bomb survivors, Hiroshima and Nagasaki. ABCC TR 1-68

Nakamura N, Kushiro J, Sposto R, Akiyama M (1989): Is variation in human radiosensitivity real or artificial? A study by colony formation method using peripheral blood lymphocytes. RERF TR $15-89$

Neriishi K, Stram DO, Vaeth M, Mizuno S, Akiba S (1989): The observed relationship between the occurrence of acute radiation sickness and subsequent cancer mortality among A-bomb survivors in Hiroshima and Nagasaki. RERF TR 18-89 
Ohtaki K, Shimba H, Awa AA, Sofuni T (1982): Comparison of type and frequency of chromosome aberrations by conventional and G-staining methods in Hiroshima atomic bomb survivors. J Radiat Res 23: 441-449

Pierce DA, Stram DO, Vaeth M (1989): Allowing for random errors in radiation exposure estimates for the atomic bomb survivor data. RERF TR 2-89

Preston DL, McConney ME, Awa AA, Ohtaki K, Itoh M, Honda T (1988): Comparison of the dose-response relationships for chromosome aberration frequencies between the $\mathrm{T} 65 \mathrm{D}$ and DS86 dosimetries. RERF TR 7-88

Roesch WC (Ed) (1987): US-Japan Joint Reassessment of Atomic Bomb Radiation Dosimetry in Hiroshima and Nagasaki. Final Report. Vols 1 and 2. Hiroshima: Radiation Effects Research Foundation

Seabright M (1971): A rapid banding technique for human chromosomes. Lancet 2: 971-972

Sofuni T, Shimba H, Ohtaki K, Awa AA (1978): A cytogenetic study of Hiroshima atomic bomb survivors. In: Evans HJ and Lloyd DC (eds). Mutagen-induced chromosome damage in man. Edinburgh University Press, Edinburgh, pp 108-114

Sposto R, Stram D, Awa AA (1990): An investigation of random errors in the DS86 dosimetry using data on chromosome aberrations and severe epilation. RERF TR 7-90

Tanaka K, Kamada N, Ohkita T, Kuramoto A (1983): Nonrandom distribution of chromosome breaks in lymphocytes of atomic bomb survivors. J Radiat Res 24: 291-304

Weisberg S (1980): Applied linear regression. John Wiley \& Sons, New York 